\title{
The Development of Instructional Leadership Indicators of Private School Principal of Laos
}

\author{
Souksamone Pathammavong \\ Ph.D. Student in Educational Administration, Udon Thani Rajabhat University
}

\begin{abstract}
The objectives of this study were: 1) to develop instructional leadership indicators, 2) to examine the goodness of fit for the structural model of instructional leadership indicators with the empirical data, and 3) to propose guidelines for the instructional leadership indicators, as developed with the empirical data. There were 728 samples. Data were collected using a rating-scale questionnaire. The statistics included mean, standard deviation, Chi-square, GFI. And AGFI.
\end{abstract}

The findings of this study can be summarized as follows: 1) the instructional leadership indicators of private school principle were classified into 5 core factors, 21 sub-factors. And 89 indicators. 2) The consistency of examining the indicators' confirmatory factor analysis model found that the models were fit to the empirical data following the hypotheses based on the statistics as follows: $\chi^{2}=115.69, \mathrm{df}=100, \mathrm{P}$-value $=$ 0.135, $\chi^{2} / \mathbf{d f}=1.16$, GFI $=0.98$, AGFI $=0.96$, CFI $=$ 1.00, $\mathrm{SRMR}=\mathbf{0 . 0 1}, \mathrm{RMSEA}=\mathbf{0 . 0 2}$ and $\mathrm{CN}=\mathbf{7 1 3 . 8 6} .3$ ) The results of the instructional leadership development comprised 69 guidelines as follows: (1) 16 guidelines for vision, (2) 15 guidelines for organizational climate, (3) 13 guidelines for curriculum development, (4) 13 guidelines for the professional development of teachers, and (5) 12 guidelines for management innovation development.

Keywords:- Indicator Development, Instructional Leadership, school administrator.

\section{INTRODUCTION}

Nowadays, progress in innovation and information technology has been continuously developed. Everything is linked by the Internet (Internet of Things), which encourages rapid change in both the economy and society. Laos is another country that has been affected by globalization and changes. Causing various development throughout, especially in the development of education Since education is a process of transferring knowledge, training makes it possible for academic and knowledge. That makes quality people Creative thinking Have problem-solving skills as a person with morals, morals, and good ethics to develop the people in the nation to the fullest potential And able to increase capacity In the higher competition (Moore, Gallagher \& Bagin, 2012: 9; Fowler, 2013: 67; Kay \& Greenhill, 2013: 2-3), the government aims to expand educational opportunities so that everyone can study throughout the country. By allowing all sectors to participate in the development of education, both the public, private and public, especially private schools with appropriate tax exemptions and tax exemption (Educational Law of Laos, 2017: 3-6 ) Resulting in the creation of a large number of private schools, which the educational administration to be successful Administrators or leaders play the most roles in managing educational resources to maximize their potential and efficiency. School administrators are real leaders, are involved in school planning, create attitudes, values, and motivation of groups and individuals, especially teachers. And educational personnel to be able to work to achieve the desired results until achieving its goal (Sunthorn Kot-Relief, 2017: 163)

Educational Management of Laos based on the needs of the society, the labor market, and the changes in the times. Both from domestic and foreign factors by defining the strategic plan for reform of the education system and standards, indicators are the criteria for quality assessment (Ministry of Education and Sports, Lao PDR, 2015: 57), but the operation still encountered problems that need to be improved and improved quality of manage especially in the quality of education management and teaching experiencing many problems (Chaiyon Khamawong, 2013: 3 ) which the academic problems of the school found that the students lack the desired qualities in analytical thinking to solve problems. Learning And the constant pursuit of knowledge, as a result, there are many schools, both public and private schools, with learners whose academic achievement is below the standard. The important thing to manage the school with higher academic quality is an important mission of the school administrators. By being responsible for providing education effectively, thinking of new management strategies, changing work styles to be in line with global changes Administrators must be aware of the mission of academic administration first. Since academic work is at the heart of the school to promote learners with quality academic achievement, achieving the specified educational goals efficiently. The standard and quality of this leadership school is called Academic Leadership (Sommai Am Donkloi, 2013: 6-8; Atchara Niyamapa, 2018: 52) Academic leadership of the school administrators. It is a characteristic of leaders who focus on and try to implement academic guidelines. By understanding how to improve and create efficiency together during the operation process working with teachers and staff creates learning focus to be able to improve teaching strategies and increase student engagement academic leadership has a positive impact on student learning and is associated with high levels of academic achievement. And make educational management of educational institutions of high quality and standards (Hallinger et al., 2018: 222-239; Adams et al., 2019: 27; DeWitt, 2020: 103). 
From the strategic education development plan of Laos, the importance of education development along with the problem condition and guidelines for development and to solve problems in academic tasks the academic leadership of the school administrators is very important and necessary for the development of educational quality and academic achievement. Therefore, the researcher is interested in developing the indicator of academic leadership of the private school administrators in Laos. To be a goal and a way to develop private school administrators to have knowledge and ability to jointly improve the quality of education in Laos.

\section{RESEARCH OBJECTIVES}

To develop indicators of academic leadership of private school administrators in Laos

To check the consistency of the academic leadership indicators of the private school administrators in Laos with empirical data

To propose guidelines for the development of academic leadership of the private school administrators in Laos

\section{RESEARCH METHODS}

\section{$>$ Population and samples}

In this research, the researcher has identified the population and sample as follows: 1) The population used in the research consisted of 534 director and academic heads of the private schools in Laos, 2 schools in each, a total of 1,068 people. 2) The sample group was the director and the academic department head of private schools. The number of 728 persons was randomly selected by using the random sampling method. And collecting data by sending questionnaires by mail, amount 728 sets

\section{Research instruments}

The research instruments used in this research were questionnaires. (Questionnaire) is a tool for data collection divided into 2 parts.

Part 1 is a survey questionnaire (Checklist) asking about the general status of the respondents, consisting of position, gender, age, and educational background.

The second part is a rating scale questionnaire with 5 levels. The questionnaire is used to ask the sample that the main components, sub-elements, and indicators of academic leadership of the private school administrators in Laos.

\section{$>$ Quality of research instruments}

Content Validity with 5 experts to examine the questions and analyze the Index of Item-objective Congruence (IOC). In this research, the questionnaires had IOC values. Equal to 1.00 every item, and the researcher used 40 sets of try out tools with confidence in each item with the value between 0.974-0.976 and the total confidence value of 0.975 which is greater than 0.70 (Patthara Pornkatesang, 2016: 117, 153)

\section{$>$ Data analysis}

The researcher used statistical software for data analysis. The statistics used were percentage, mean, standard deviation, Correlation Co-efficiency, KMO (Kaiser-meyer-olkin Measure of Sampling Adequacy), Bartlett's Test of Sphericity, composition weight ( Factor Leading) and construct the composition by using the Factor Score of the indicator is the creation of the linear sum of the indicators or observed variables and the analysis of confirmed elements (Confirmatory Factor Analysis). Statistical values check the consistency of the model with empirical data such as chi-square. Acceptance level is Pvalue greater than .05 . Relative chi-square value (/ df) is less than 2.00. Adjusted Goodness of Fit Index (AGFI) greater than.90 Comparative Fit Index (CFI) greater than .95 Critical N: CN of more than 200 roots of the square mean of Remnants in the form of standard scores (Standardized Root Mean Square Residual: SRMR) and Root Mean Square Error of Approximation (RMSEA) less than .05 (Suchart Prasitrathsin, 2008: 15-17).

\section{$>$ Proposing guidelines for academic leadership development}

Proposing guidelines for the development of academic leadership through focus group discussions with experts with knowledge and experience in educational administration.

\section{RESEARCH FINDINGS}

The results of the development of academic leadership indicators of private school administrators in Laos the development of academic leadership indicators found that there are 5 main components, 21 sub-elements and 89 indicators which are as follows

- Vision There are 4 sub-components with 16 indicators as follows

$\checkmark$ The mission analysis of the school has 4 indicators

$\checkmark$ The educational institution's goal-setting has 4 indicators

$\checkmark$ The decision has 4 indicators

$\checkmark$ Responsibility with 4 indicators

- Atmosphere of the organization, there are 4 subelements, 16 indicators as follows

$\checkmark$ Building trust with 4 indicators

$\checkmark$ Motivation with 4 indicators

$\checkmark$ Promotion of teaching and learning process with 4 indicators

$\checkmark$ Providing warmth and support with 4 pieces

- Curriculum Development There are 5 components, 20 indicators as follows

$\checkmark$ Basic data analysis has 4 indicators

$\checkmark$ Setting goals with 4 indicators

$\checkmark$ Content selection has 4 indicators

$\checkmark$ The program has 4 indicators

$\checkmark$ Assessment of curriculum use with 4 indicators 
- In the development of teachers to professionals, there are 4 sub-components, 17 indicators as follows

$\checkmark$ Teacher competency development has 5 indicators

$\checkmark$ Building a learning community with 4 indicators

$\checkmark$ Coaching has 4 indicators

$\checkmark$ Inspiration has 4 indicators

- In the development of service innovation, there are 4 sub-elements of 17 indicators as follows

$\checkmark$ Production of innovation and the use of technological innovation and technology with 5 indicators

$\checkmark$ Building a learning organization with 5 indicators

$\checkmark$ Knowledge management has 6 indicators

$\checkmark$ Self-development with 4 indicators

The results of the consistency testing of the academic leadership indicator structure model of the private school administrators in Laos with empirical data

The consistency testing of the academic leadership structure model shows that the results of the analysis of the sub-elements show that the total weight of all 21 subelements is positive and greater than 0.30 , with values ranging from 0.69 to 0.94 and statistically significant. At every level of .05 , which shows that all 21 sub-elements are important components of the main components Which the said sub-components have the proportion of variance explained by the sub-elements Or the prediction coefficient from 0.48 to 0.88 and can analyze the composition of the academic leadership indicators of the private school administrators in Laos with 5 empirical data, 21 subelements (Figure 1).

From the analysis of the confirmation components of the structural equation model of the academic leadership component, it was found that after the consistency of the model was adjusted very consistently with the empirical data. Considered from the chi-square statistic, 115.69 is not statistically significant. The df value is 100 . When considering the relative chi-square, $1.16 \mathrm{GFI}$ is 0.98, AGFI is $0.96, \mathrm{CFI}$ is 1.00. SRMR is 0.01 RMSEA is equal. 0.01 and the $\mathrm{CN}$ value of 713.86 show that the equation model for the main components of academic leadership of the private school administrators in Laos consistency in harmony with empirical data

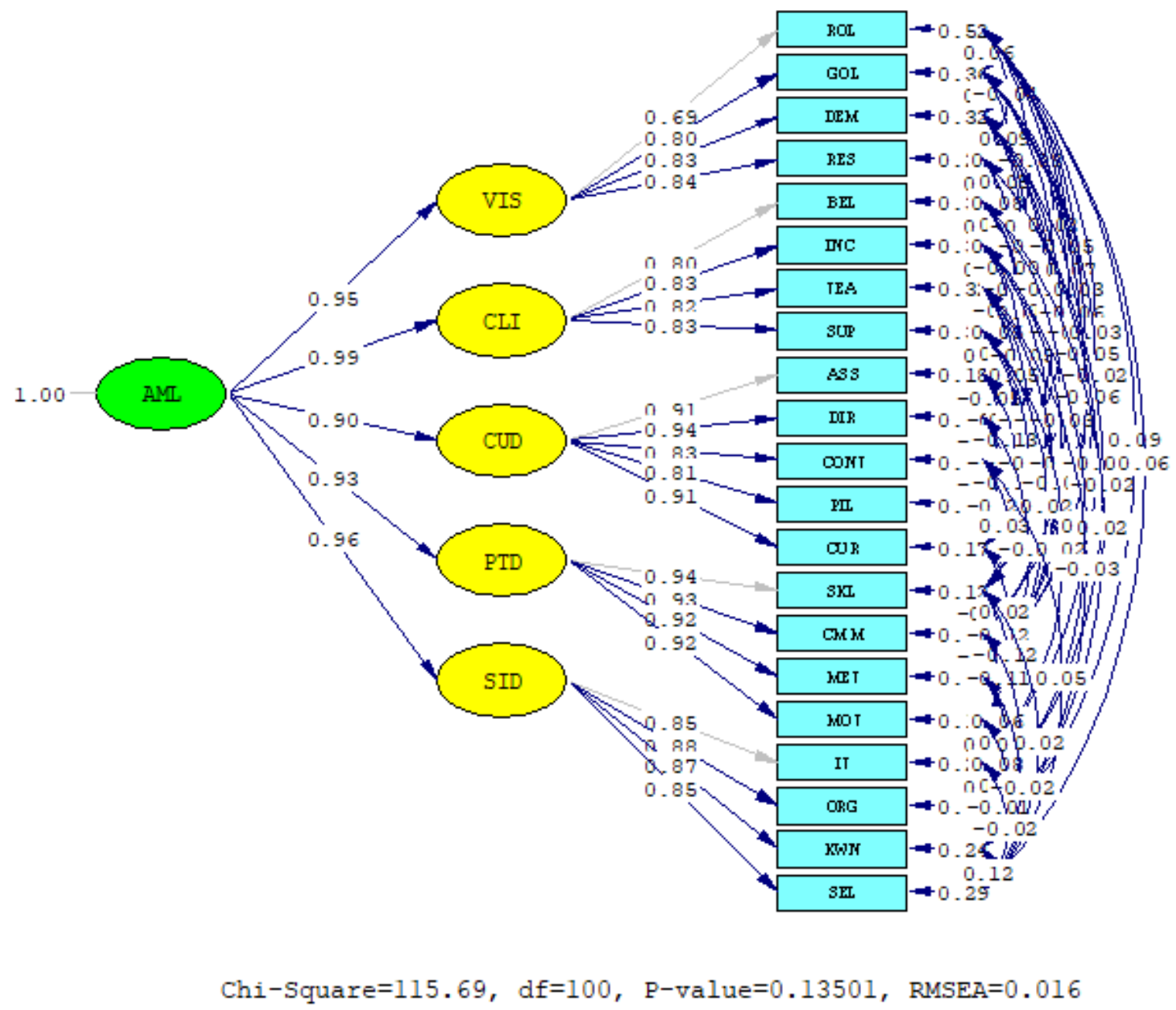

Fig 1:- Confirmatory component model of academic leadership of the private school administrators in Laos. 
Guidelines for the development of academic leadership of the private school administrators in Laos

From the development of academic leadership indicators of private school administrators, the 69 guidelines were used to develop academic leadership development of administrators as follows:

- There are 16 ways to look at vision, including work planning. There must be an analysis of the organization to find SWOT or TOWS. When the analysis results are known. Therefore, planning to prepare strategies by collaborating with teachers, personnel, and stakeholders to formulate strategies, visions, missions, key objectives projects, and indicators to be consistent and with the same goal, there is consideration to the needs of students. Parents and communities in strategic planning, a plan with a vision there is a clear long-term goal setting. Make plans to manage existing budgets to maximize benefits for teaching and learning activities with analysis of the future and competitive thinking in high adjustment to keep up with the changes that occur according to changes in the global society, the school administrator must be responsible for the administration and academic obligations that are appropriate. Dedicate time to the government and pay attention to duties and academic administration with full knowledge and capability. Provide opportunities to promote and support equipment and supplies Facilities that facilitate work for personnel

- Atmosphere, the organization has a total of 15 approaches, which are to build confidence in the administration and to comply with the agreements provided. There is an opportunity for all teachers to work together fully. By having to recognize and accept differences between people, there is an incentive to encourage teachers to progress in their careers better. Give an opportunity to freely show the work or creativity about the teaching and learning with consideration of merit to raise a salary fairly Including the rejoicing of successful teachers or have an outstanding work including development, procurement, promotion of technology and innovation for creating modern teaching media the school administrators are consultants to give suggestions on how to solve problems correctly.

- Curriculum development there are 13 ways in which the school administrators and teachers should analyze basic information and various community problems to be used to develop curriculum development to provide learners with desirable characteristics that are suitable and in line with their age requirements ability of learners and the needs of the community educational, standards the aims and guidelines for curriculum development are consistent with educational policies. National education management and the national economic development plan of education. The content is selected about the specified learning objectives. The subject content is ranked by considering the continuity and difficulty of the subject including a selection of content for teaching and learning that is modern and up to date with current changes, there is training to understand the curriculum before implementing it then take the course experiment. There is supervision, supervision, and follow-up of the course trial. Regularly In which the program can apply the knowledge gained the students who graduate are in line with the program set.

- The development of 13 professional teachers, including the development of teachers' competency in the field and the teacher development plan in the school development plan and annual plan allocates funds for the development of teachers to have competency according to their professional field and vocational competency, in-house training Other agencies Or study trips from various learning sources for new academic knowledge to create a learning community to be used as a guideline in promoting and developing teachers to have an exchange of knowledge until becoming a learning community. The school administrators have job coaching. Guidance or advisor in the development of work clearly, to be the most effective and effective by inspiring teachers to be committed and have effort in working to achieve quality success and maximum benefits for both students and the organization

- Innovation development, 12 management approaches, namely the production of innovation and the use of innovation and academic technology by using innovations and technology for academic administration inside and outside the school training, organize seminars or send personnel to upgrade to keep up with current conditions modern equipment is used in teaching and learning in their school organization and information is not new from various media. Promote the learning of teachers to be knowledgeable people in their work, to have a systematic pattern and a process for developing learning sources, disseminating knowledge easily accessible and there is knowledge management so that knowledge can be used to develop new experiences constantly Including requiring the exchange of opinions And continuous and consistent experience support self-development Including the exchange of professional opinions and others. With colleagues and different fields always must have organizational and professional development through innovation to be used appropriately.

\section{DISCUSSION}

The development of the model structure of theoretical indicators for the academic leadership of private school administrators in Laos

From the synthesis and development of theoretical indicators of academic leadership of private school administrators in Laos. The results of the research showed that there are 5 main components, 21 sub-elements and 89 indicators due to the development of the melting of similar elements into the same group according to the expert's advice. So that similar or similar indicators are combined 
into one component for greater clarity. And lead to the development of school administrators in the same direction the main components of the theoretical indicators of the academic leadership of the private school administrators in Laos have 5 main components which are 1) vision, 4 subelements, and 16 indicators. School mission analysis defining the school's goals, decisions, and responsibilities. This is consistent with the research (2010: 94-96). The study of executive leadership behaviors found that the important academic leadership factors of school administrators are creating vision. And the research of Bernal \& Ibarrola-García (2014: 94), studying the learning leadership from teaching, found that the important characteristics of the academic leadership of the school administrators are the vision and the depression. deep collaboration to develop a comprehensive school vision and mission Compliance with vision and mission It also corresponds to Carrier's research (2011: 106-118). What are the study of academic leadership and its characteristics? In practice, the characteristics of the academic leadership characteristics of the school administrators are the all-round development to School vision and mission and following the research of Rescigno (2015: 205) studied the network with a vision found that the vision of the school administrators. There are important indicators, including the organization's goals. Organizational analysis Policy development Using innovation in management accountability And decision making. 2) At the organizational climate, there are 4 sub-elements and 16 indicators, with indicators relating to building trust. Motivation Promoting the teaching and learning process Warming and support Which is in line with the concept of Chen (2014: 33) that says Academic leadership characteristics must create an atmosphere in the organization. And in line with the concept of Davis (1989: 451-452) said that the atmosphere of a good organization. Must have the following components mutual trust and opportunities for progress which are motivated to work Consistent with the research of Somchit Pity (2009: 156), studying the development of linear structural relationship model of the factors influencing the effective empowerment of teachers found that creating an organizational climate has indicators. Important point is to build trust. Each other And warmth and support. 3) Curriculum Development there are 5 components, 20 indicators, with indicators for basic data analysis. Determination content selection trial course and evaluation of course use in line with research (2016: 30-47) studying academic leadership: the role of school administrators in managing teaching and learning programs. The important characteristics of important academic leadership consist of indicators of Create a course assessment administration and administration of curriculum. Curriculum coordination participation in the course content review and applying the curriculum consistent with Hicks (2014: 70) research on the academic leadership approach of Louisiana primary and secondary schools, it was found that academic leadership characteristics of school administrators include cocurricular development. And following the research by Hallinger et al. (2017: 222-239) conducted a study of views on important academic leadership in Vietnam: the preliminary model found that the key indicators of academic leadership behavior are Joint course development Curriculum and Instruction Management 4) In the aspect of teacher development to professional, there are 4 subcomponents, 17 indicators, with indicators about teacher competency development. Creating a learning community, teaching, and inspiring. This is consistent with Imhangbe's research (2011: 57-58). The study of the impact of important leadership on student achievement is the school administrators who develop teachers to be professional teachers. And in line with the Hoy \& Hoy (2013: 2-3) concept that addresses the important characteristics of academic leadership of school administrators, namely the competency in the development and promotion of teachers to professionals. By having incentives for learning and following Lindsey's research (2015: 129) studied teacher preparation to the classroom in the 21 st century, the case of digital demographic study found that the development of teachers to professionals, teachers should have indicators about how to encourage teachers to use. Technology for learning management encourages teachers to use a variety of media to inspire teachers to become aware of learning management and coaching. 5) In the development of service innovation, there are 4 sub-elements, 17 indicators, with indicators about the production of innovation and the use of innovation and Academic technology creating a learning organization knowledge management and personal development this is in line with Matthew (2014: 95) 's concept of academic leadership.

$>$ The harmonization of academic leadership indicators and empirical data of private school administrators. In the people's democratic republic

From the study found that Indicator of academic leadership of private school administrators In the developed democratic republic of Laos is consistent with the empirical data Because they meet the analysis criteria, they are consistent with the empirical data. This may be because it has been mentioned that if the theory has been carefully examined in both international research and research in Thailand And gathered data from interviews with academics Operator Or expert As mentioned And bringing the information together. Therefore, the developed model should be consistent with the empirical data. This is in line with the idea of the characteristics of good indicators of Virojsarnrattana (2013: 201) which has proposed that Good indicators should be of quality by the following criteria. It is accurate in the content (Content Validity) to be used as an indicator. Construct validity there are methods for selecting variables, combining and determining the weight of the correct variable. Validity can be measured in the things that need to be measured. And can be compared and reliable (Reliability). The value obtained, both quantitative and qualitative, should be consistent. If measuring the same thing Regardless of the groups that measure And in line with the concept of the characteristics of the good indicators of Thipsiri Kanchanawati and Sirichai Kanchanawati (2016: 84-86) which proposed that good indicator When tested, the quality must meet the criteria that are validity (Validity) must be measured in the things that can be measured accurately, precisely, to the point, and 
is a representative of the assessment subject, with certainty (Reliability) must be measured. Stable as before, as multiple-choice, can be matched or similar every time being neutral (Neutrality) must be neutral, not biased or directed in any direction In evaluating the opportunity to easily be biased because the information is collected from a sensitive stakeholder (Sensitivity) in the measurement of anything, if the indicator is sensitive to the difference in detail such as multiple levels Increasing the quality of the measurement results and easy to use (Practically) indicators can be used to measure or store data in real ways with ease. And once the data has been collected, can be easily interpreted

Guidelines for the development of academic leadership of the private school administrators in Laos

From the guidelines for the development of academic leadership of the private school administrators, there are a total of 69 ways as follows: (1) Vision has 16 ways (2) Organization climate has 15 ways (3) Program development has 13 ways (4) In the aspect of teacher development to professional 13 ways and (5) in the development of administrative innovation, there are 12 methods, which are developed to be in line with the national education development plan. And the 8th National Economic and Social Development Plan (2016-2020) that needs a way to escape from countries with the least developed status. From the guidelines for the development of academic leadership Consistent with the research of Thianphat Chupawa (2016: 104-105), studying the guidelines for the development of academic leadership of the private vocational college administrators in Bangkok, found that the guidelines for the development of academic leadership consist of enhancing the atmosphere and culture that is conducive to student learning Must start from the development of knowledge. Understanding about staff motivation for network management behavior must start by studying about creating and using the network systematically with service innovation developed the vision in management professional teacher and curriculum development

\section{SUGGESTION}

\section{$>$ Suggestions for using research findings}

From the development of academic leadership indicators, it is found that there are 5 main components, 21 sub-elements, and 89 indicators, thus suggesting the use of research results as follows

- The results of this research give an indicator of academic leadership which is in line with the role of the private school administrators in Laos, which can be used to assess the administration of the duties of Private school administrators by the changing context of education, society, economy, and digital technology, and may be used to evaluate administrators in other departments.

- The agency may use the indicators from the research to apply as a guideline for the development of leadership of the school administrators and educational personnel at different levels or may be used as a guideline for the development of the criteria for human consideration to the position of educational administrator

- Leaders in higher-education agencies, private schools may use the elements and indicators from the research to determine future academic leadership behavior.

\section{$>$ Suggestions for further research}

- Research and development should be carried out by using the model validated in this research as a guideline for the academic leadership training package for school administrators in Laos.

- There should be a study to monitor the stability of the characteristics, indicators, and components according to the structural model obtained from this research, the independence of the components and the apparent change of the various components to create a model explaining the development of academic leadership indicators of private school administrators in Laos.

- The indicator of academic leadership of basic school administrators or government educational institutions should be developed at different levels, including preschool education, elementary school age, and general education level in Laos.

\section{REFERENCES}

[1]. Adams, D., Piaw, C.Y., Lee, K.C.S. \& Sumintono (2019). Instructional leadership to the fore: research and evidence. Kuala Lumpur: University of Malaysia Press.

[2]. Bernal, A. \& Ibarrola-García, S. (2014). Learning leadership from teaching: emotional competences. Multidisciplinary Journal for Education, Social and Technological Sciences, 1(2), 33-52.

[3]. Carrier, L. (2011). What is instructional leadership and what does it look like in practice? amulticasesase study of elementary school principals who have led schools from being identified as under performing to performing. Doctoral dissertation, University of Massachusetts Amherst.

[4]. Cheatham, T. (2010). The relationship between principals, leadership behavioursand student academic performance in four classifications of schools. Master thesis, Mercer University.

[5]. Chen, S. (2014). Why the leadership of change is especially difficult for Chinese principals: A macroinstitutional explanation. Journal of Organizational Change Management, 27(3), 486-498,

[6]. Davis, I.L. (1989). The relationship between satisfaction with leadership and school climate in randomly ruraly Gregia public elementary school. Dissertation Abstracts International, 50(10A), 31-15.

[7]. DeWitt, P.M. (2020). Instructional leadership: creating practice out of theory. Thousand Oaks, CA: Sage Publications.

[8]. Educational Law of Laos.) 2017). Education and schools in LAOS. Retrieved March 20, 2019, from http://factsanddetails.com/southeastasia/Laos/sub5_3d/ entry-2981.html 
[9]. Fowler, F.C. (2013). Policy studies for educational leaders. $4^{\text {th }}$ ed. Burlington: Pearson Education.

[10]. Gunawan, I. (2017). Instructional Leadership Profile of Junior High School's Principal (A Case Study of Junior High School in Malang). International Research-Based Education Journal, 1(1), 64-68.

[11]. Hallinger, P., Adams, D., Harris, A. \& Suzette, J.M. (2018). Review of conceptual models and methodologies in research on principal instructional leadership in Malaysia: A case of knowledge construction in a developing society. Journal of Educational Administration, 56(1), 104-126.

[12]. Hallinger, P., Walker, A., Nguyen, D.T., Truong, T. \& Nguyen, T.T. (2017). Perspectives on principal instructional leadership in Vietnam: a preliminary model. Journal of Educational Administration, 55(2), 222-239.

[13]. Hicks, M. (2014). Instructional leadership practices of Louisiana elementary and middle school principals. Louisiana: ProQuest Dissertations Publishing.

[14]. Hoy, A.W. \& Hoy, W.K. (2013). Instructional leadership. $4^{\text {th }}$ ed. Boston: Omegatype typography.

[15]. Imhangbe, S. (2011). Impact of principal leadership on catholic high school students' academic achievement in Edo State, Nigeria. Doctoral dissertation, Fordham University.

[16]. Kay, K. \& Greenhill ,V. (2013(. The leader's guide to 21st century education: 7 steps for schools and districts. London: Pearson.

[17]. Lindsey, L.A. (2015). Preparing teacher candidates for 21 st century classrooms: A study of digital citizenship. Doctor of education, Arizona State University.

[18]. Manaseh, A.M. (2016). Instructional leadership: The role of heads of schools in managing the instructional program. International Journal of Educational Leadership and Management, 4(1), 30-47.

[19]. Matthew, R.F. (2014). Leadership and Organizational Strategy. University of South Dakota, Vermillion.

[20]. Matthew, R.F. (2014). Leadership and Organizational Strategy. Vermillion: University of South Dakota.

[21]. Ministry of Education and Sports, Lao PDR. (2015). Education and sports sector development plan (20162020). Retrieved March 20, 2019, from http://www.dvv-international.la/fileadmin/files/southand-southeast-asia/documents/ESDP_2016-2020EN.pdf

[22]. Moore, E.H., Gallagher, D.H. \& Bagin, D.R. (2012). The school and community relations. $11^{\text {th }}$ ed. London: Pearson.

[23]. Rescigno, R.W. (2015). A case study of the launch of Delaware's vision network: An initiative of vision 2015. Doctor of education, Wilmington University. 